\title{
Learning to Be Difficult: Civic Education and Intransigent Indignation
}

\author{
Claudia W. Ruitenberg (University of British Columbia)
}

\begin{abstract}
:
The 'age of Trump' has made me appreciate anew the uncompromising political thought of Jacques Rancière. In this short essay, I argue that rage and resentment are not the only politically relevant forms of anger, and that intransigence and indignation are the forms of anger that feature prominently in Rancière's conception of political disagreement.
\end{abstract}

\section{Introduction}

In past work, I have argued that anger is a significant emotion driving political action, and that it ought to be included in political education. I have written, for instance, that "educating the political emotions ... requires the development of a sense of solidarity, and the ability to feel anger on behalf of injustices committed against those in less powerful social positions" (Ruitenberg, 2009, p. 277). I have proposed that "disagreement ought to be fostered as a democratic capacity, not neutralized or suppressed" (Ruitenberg, 2010, p. 49) and that such disagreement is affectively charged, because "asking students to imagine the society in which they would like to live can lead them to be disappointed with or angry at the current order (p. 51).

In the "age of Trump," which I take to span from the start of his election campaign until the end of his presidency, concern has been raised about the explosive presence of anger, both in Trump's own speech and writing, and in that of Trump supporters. In a 2016 interview for The Atlantic, Martha Nussbaum suggests that

what Trump has found, and very cleverly so, is that there's a lot of helplessness out there in the middle of America: People who feel they're not doing as well as they want; people who aren't doing as well as their parents did. Jobs are going to China; jobs are going to other countries. He makes them feel that if they turn their helplessness into rage, they will accomplish something (in Green \& Nussbaum, 2016).

Pankaj Mishra's (2017) Age of Anger, in which he explores "a particular climate of ideas, a structure of feeling, and cognitive disposition, from the age of Rousseau to our own age of anger" (p. 28, emphasis in original) also makes explicit reference to Trump and his supporters. Mishra writes: "Demagogues of all kinds, from Turkey's Recep Tayyip Erdogan to India’s Narendra Modi,
France's Marine Le Pen and America's Donald Trump, have tapped into the simmering reservoirs of cynicism, boredom and discontent" (p. 8). He gives further insight into the main form of "simmering" anger that is the focus of his investigation when he writes:

An existential resentment of other people's being, caused by an intense mix of envy and sense of humiliation and powerlessness, ressentiment, as it lingers and deepens, poisons civil society and undermines political liberty, and is presently making for a global return to authoritarianism and toxic forms of chauvinism (p. 14).

Much more can be said about Mishra's analysis, but for my purposes here, I mainly want to underscore the difference between the forms of anger both he and Nussbaum decry as unproductive, namely rage and resentment, and the forms of anger I believe can play a more positive role in political education.

The 'age of Trump' has made me appreciate anew the uncompromising political thought of Jacques Rancière. In this short essay, I argue that rage and resentment are not the only politically relevant forms of anger, and that intransigence and indignation are the forms of anger that feature prominently in Rancière's conception of political disagreement. If the 'age of Trump' is giving anger a bad name, we would do well to expand our understanding of various forms of anger, rather than dismissing its relevance to democratic politics and democratic political education altogether.

\section{Compromise and Intransigence}

In responding to the theme of "civic education after Trump,' I must make it clear from the outset that I am interested only in civic education that has a clear political focus - as opposed to those forms of civic education that 
privilege the social dimensions of community-mindedness, volunteerism and 'civic spirit.' As I have argued elsewhere (Ruitenberg, 2015), I believe civic education must have a clearly political orientation; in this essay I want to further flesh out what this 'political' orientation means in Rancière's somewhat unusual conception of 'politics.'

For Rancière (1995/1999), "politics exists when the natural order of domination is interrupted by the institution of a part of those who have no part" (p. 11). By this he means that politics exists when, in a contingent social order, those who have been excluded from or marginalized within that order form an identifiable group that can render their exclusion or marginalization visible. I might put it this way: politics occurs when "those who have no part" call bullshit on the justifications they are given for their unequal treatment and expose "the sheer contingency of the order, the equality of any speaking being with any other speaking being" (p. 30). When that group succeeds in reconfiguring the contingent social order so that they are included as equals, this is a political intervention. Calling bullshit on explanations for inequality until "the absence of $\operatorname{arkh} \vec{e}$ " (p. 15), that is, the absence of a fundamental ground or justificatory source for that inequality, is exposed, requires intransigent indignation. The names of recent political movements that expose the unjustified and unjustifiable perpetuation of the unequal treatment of equals illustrate this intransigent indignation: the Indignados in Spain, 'Idle No More' in Canada, 'Black Lives Matter' and 'Time's Up' in the United States.

Disagreement that leads to an intervention of a political nature, for Rancière, is a disagreement over a "wrong" (tort), that is, over a fundamental lack of recognition of a person's or group's equality. The political intervention that finally brings about the recognition of equality is not a debate or negotiation, in which two parties exchange arguments and find some sort of common ground or compromise, nor is it a raging fight in which the parties resort to verbal or physical violence. Instead, it is an intransigent insistence on equality. On equality, no compromise is possible: one either is or is not recognized as an equal. Any offer that falls short of full recognition of equality must therefore be rejected.

Politically oriented civic education, not only but perhaps especially in the age of Trump, requires young people to be able to see, be indignant about, and expose the flawed justifications for inequality. This involves educating citizens (or 'political subjects,' if you prefer) to be 'difficult' in cases where a person's or group's equality is not recognized. I understand the energy required to fuel the insistence on equality, the refusal to move, the intransigent indignation as a kind of anger, but it is obviously a different kind of anger from the rage and resentment chronicled by Mishra and demonstrated by Trump.

\section{Rage and Indignation}

As noted, both Nussbaum and Mishra argue against anger that takes the form of rage. Nussbaum further argues that anger necessarily involves vengefulness: "Aristotle, and every other philosopher known to me who writes about anger, says that part of anger itself is a desire for payback. Without that desire, it's not really anger-it's something else" (in Green \& Nussbaum, 2016).

I take a broader view of anger, one that does not hinge on either rage or vengefulness, and that takes as its point of departure the idea that anger is a feeling or affect that makes us want to change something that we perceive as a wrong. Anger can be felt in response to a wrong done to oneself, but also in response to a wrong done to others, and the primary desire fuelled by anger is for the wrong to stop. This desire is not, in my view, necessarily accompanied by any desire for retribution against whomever or whatever was the source of the injustice. At its core, anger is the feeling that accompanies the perception that a fundamental line has been crossed, an injustice has been done, and the situation has to stop. While anger can arise from perceptions of both moral and political wrongs, in this essay I am interested only in political anger, not moral anger. In earlier work I have written:

"Moral anger could be the anger or indignation one feels after seeing moral values one cherishes violated; when one reads in the paper how a person in need was treated harshly rather than with compassion, for example, or when one witnesses a parent unfairly chastising a child. Political anger, however, is the anger or indignation one feels when decisions are made and actions are taken that violate the interpretation and implementation of the ethico-political values of equality and liberty that, one believes, would support a just society" (Ruitenberg, 2009, p. 277).

The phrase "the interpretation and implementation of the ethico-political values of equality and liberty" is a reference to Chantal Mouffe's work on agonistic pluralism, which argues that liberty and equality are the basic values that must underpin a pluralist democracy. The agon or persistent democratic conflict revolves around the interpretation and implementation of these fundamental values.

In reference to Rancière's work, I might say that political anger is the anger or indignation one feels when the line that has been crossed is the line between equality and inequality. When one finds oneself treated as an unequal, or one sees another treated as an unequal, this can provoke an indignation that motivates intransigence, steadfastness, the ability to hold one's ground or to claim the ground one was denied.

Potegal and Novaco (2010) discuss a range of words used by the ancient Greeks for "anger": "Besides Mènis 
and Nemesis, there is chalepaino (annoyance), kotos (resentment), cholos (bitterness, literally "bile"), thumos (in the more general context of zeal or energy), orge for intense anger, sometimes bordering on madness, and others" (pp. 13-14). It is thumos that most closely approximates what I call political anger, and I have previously referred to Barbara Koziak's work on thumos as a political emotion (see Ruitenberg, 2009). While the meaning of thumos is by no means unequivocal and changes over time, there is some support for my reference to thumos as the kind of anger that can fuel peaceful but intransigent political resistance. As William Harris (2001) writes, "In the Laws, Plato seems to say that anger is necessary against wrongdoing (v.731b), but this is thumosanger, indeed thumos gennaios ("noble anger"), and it is plain that he would not have written orgē quite as readily" (p. 92).

\section{Intransigent Indignation and Political Action}

As Todd May (2010) has documented, many political movements have been sparked or marked by significant moments in which someone has physically refused to move:

The historical case ... is the series of lunch-counter sitins in the US during the civil rights movement. African Americans sat at lunch counters that were restricted to whites and tried to order lunch. It is hard to imagine a more crystalline example of acting collectively from the presupposition of equality. The message of the lunch-counter sit-ins was clear: those who sat down to order a meal presupposed themselves to be equal to those who were permitted to order meals (p. 25).

The history of political resistance across the world provides many such examples of people treated as unequal refusing to accept such treatment. African American James Meredith's insistence on registering at the University of Mississippi in 1962; Quechua Felipe Guaman Poma de Ayala's letter to the Spanish king in 1613, correcting the King's misconceptions about the Spanish colonial occupation and including "a mock interview in which he advises the King as to his responsibilities" (Pratt, 1992/2003, p. 2); Jeanne Deroin presenting "herself as a candidate for a legislative election in which she cannot run" in 1849 in France (Rancière, 1995/1999, p. 41); no matter how disparate the places and times, it is the repeated refusal, the stubborn refusal to move out of the way or to accept any compromise offered, that has, eventually, brought about the recognition of people's fundamental equality.

\section{Intransigent Indignation and Political Education}

The educational question is whether such intransigent insistence on equality can or needs to be taught. Rephrasing the question, I might ask under what conditions political subjects are most likely to discern inequality and to develop the knowledge, skills, and dispositions that will allow them to respond to it with intransigent indignation.

The title of this essay suggests that citizens (or people, more generally) should learn to 'be difficult.' By this I do not mean, of course that they (we) should learn to be difficult in all situations. What I have in mind is something more specific, namely the ability and willingness to be difficult or call bullshit in situations where the existing social order is not willing to honour or even hear a person's or group's demand for recognition of their equality. The demand may be met with suggestions that it is too much too soon, that people need time to adapt, or that more studies are needed. In those cases, people should be able and willing to be intransigent. A compromise will not do, because on equality, no compromise is possible.

\section{Educating Civic Killjoys}

What I have in mind is a civic killjoy, modelled on the "feminist killjoy" described by Sara Ahmed (2010). Ahmed describes the "feminist killjoy" as "an affect alien, estranged by happiness" (p. 581), and she is referring to the happiness expected of a woman in socially prescribed situations. "The feminist killjoy spoils the happiness of others; she is a spoilsport because she refuses to convene, to assemble, or to meet up over happiness" (p. 581). The civic killjoy is similarly an affect alien, estranged by the happiness - and, I would add, gratitude - expected by others in the community or polity for the possibility of civic participation or the offer of a compromise. The civic killjoy cannot be happy with mere civic participation that does not entail the real possibility of political change, nor can the civic killjoy be happy with a compromise that falls short of an unequivocal recognition of equality.

Where some civic education sees civic 'participation' as one of the main desired outcomes, the conception of politically oriented civic education I have proposed is not content with participation, especially if, as Rancière cautions, "political 'participation' is just the mask of the allocation of lots" (p. 83), i.e., of unequal places in the existing social order. Learning to be difficult, to be a "civic killjoy," involves the ability to see and the disposition to act on the wrong that is unequal treatment in the absence of a proper justification for inequality, and this acting may include refusing to participate on terms that perpetuate the wrong. 
Ahmed, S. (2010). Killing joy: Feminism and the history of happiness. Signs: Journal of Women in Culture and Society, 35(3), 571-594. https://doi.org/10.1086/648513

Green, E., \& Nussbaum, M. (2016, May 7). The anger of the American people. The Atlantic. Retrieved from https://www.theatlantic.com/politics/archive/2016/05/martha-nussbaum-anger/481464/

Harris, W. V. (2009). Restraining rage: The ideology of anger control in classical antiquity. Harvard University Press. https://doi.org/10.4159/9780674038356

May, T. (2010). Contemporary political movements and the thought of Jacques Rancière: Equality in action. Edinburgh University Press. https://doi.org/10.3366/edinburgh/9780748639823.001.0001

Mishra, P. (2017). Age of anger: A history of the present. Farrar, Straus and Giroux.

Potegal, M., \& Novaco, R. W. (2010). A brief history of anger. In M. Potegal, G. Stemmler, \& C. Spielberger (Eds.), International handbook of anger: Constituent and concomitant biological, psychological, and social processes (pp. 9-24). Springer. https://doi.org/10.1007/978-0-387-89676-2_2

Pratt, M. L. (2003). Imperial eyes: Travel writing and transculturation. Routledge. https://doi.org/10.4324/9780203106358 (Original work published 1992)

Rancière, J. (1999). Disagreement: Politics and philosophy (J. Rose, Trans.). University of Minnesota Press. (Original work published 1995)

Ruitenberg, C. W. (2009). Educating political adversaries: Chantal Mouffe and radical democratic citizenship education. Studies in Philosophy and Education, 28(3), 269-281. https://doi.org/10.1007/s11217-008-9122-2

Ruitenberg, C. W. (2010). Conflict, affect and the political: On disagreement as democratic capacity. In Factis Pax, 4(1), 4055 .

Ruitenberg, C. W. (2015). The practice of equality. Democracy \& Education, 23(1), 1-9.

\section{Recommended Citation}

Ruitenberg, C. W. (2018). Learning to be difficult: Civic education and intransigent indignation. On Education. Journal for Research and Debate, 1(1). https://doi.org/10.17899/on_ed.2018.1.5

\footnotetext{
About the Author

Claudia W. Ruitenberg is Professor in the Department of Educational Studies at the University of British Columbia. Previous publications include Unlocking the World: Education in an Ethic of Hospitality (2015), Reconceptualizing Study in Educational Discourse and Practice (edited, 2017), and Education, Culture and Epistemological Diversity: Mapping a Disputed Terrain (co-edited with D. C. Phillips, 2012).
} 